International Journal of Software Engineering \& Applications (IJSEA), Vol.1, No.4, October 2010

\title{
Problem Based Learning (PBL): Analysis of CONTINUOUS STIRRED TANK CHEMICAL REACTORS With A Process CONTROL APPROACH
}

\author{
Regalado-Méndez Alejandro ${ }^{1}$, Cid-Rodríguez Ma. del Rosario P. ${ }^{2}$, and \\ Báez-González Juan G. ${ }^{3}$ \\ ${ }^{1}$ Industries Institute, Universidad del Mar, Puerto Ángel, Oaxaca, México (Present \\ address: 1315 S. Main St., Santa Ana, CA, 92707) \\ alejandro.regalado33@gmail.com \\ ${ }^{2}$ Ecology Institute, Universidad del Mar, Puerto Ángel, Oaxaca, México \\ rosarita_cid@hotmail.com \\ ${ }^{3}$ Food Science Department, FCB, Universidad Autónoma de Nuevo León, \\ Nuevo León, México \\ juan.baezgn@uanl.edu.mx
}

\begin{abstract}
This work is focused on a project that integrates the curriculum such as thermodynamic, chemical reactor engineering, linear algebra, differential equations and computer programming. The purpose is that students implement the most knowledge and tools to analyse the stirred tank chemical reactor as a simple dynamic system. When the students finished this practice they should have learned about analysis of dynamic system through bifurcation analysis, hysteresis phenomena, find equilibrium points, stability type, and phase portrait. Once the steps were accomplished, we concluded that the purpose was satisfactorily reached with an increment in creative ability. The student showed a bigger interesting in this practice, since they worked in group. The most important fact is that the percentage of failure among students was $10 \%$. Finally, using alternative teaching-learning process improves the Mexican system education.
\end{abstract}

\section{KEYWORDS}

Bifurcation, Equilibrium Point, Hysteresis, PBL, and Phase Portrait

\section{INTRODUCTION}

An important goal of the undergraduate curriculum in engineering is to develop the integration, design, and evaluation capabilities of the student. As shown in Figure 1, Bloom in 1956 characterized the six cognitive levels in the hierarchy: Knowledge $\rightarrow$ Comprehension $\rightarrow$ Application $\rightarrow$ Analysis $\rightarrow$ Synthesis $\rightarrow$ Evaluation. The cognitive skills at the highest level are synthesis and evaluation, which rely on comprehension, application, and analysis capabilities in the knowledge domain, and are consequently the most difficult and challenging to teach. However, to prepare undergraduates to be effective designers in industry, it is important to ensure an adequate coverage of these higher-level skills, rather than limiting their education to one based on just knowledge, comprehension, application, and analysis [16].

Before mentioned that, in engineering education there is a shift in emphasis from professional skills to process skills [8]. These skills include problem analysis and problem solving, project management and leadership, analytical skills and critical thinking, dissemination and communication, interdisciplinary competencies, intercultural communication, innovation and creativity, and social abilities [12]. 


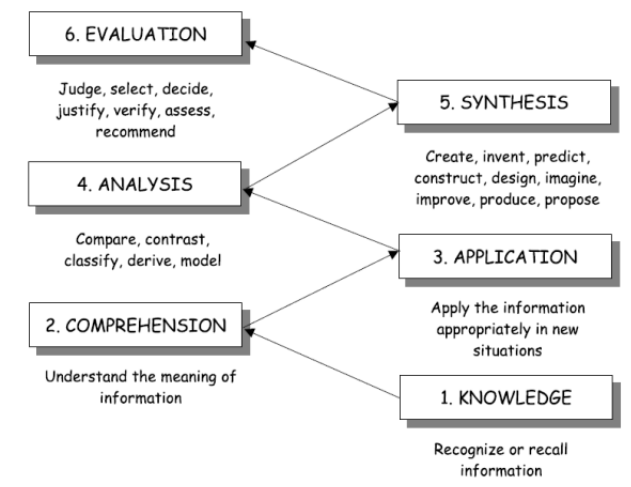

Figure 1. Bloom's taxonomy of educational objectives [3] [16].

In this sense, we have ensuring that future engineers think differently and with a broader perspective, is perhaps the more pressing issue in undergraduate education. Moving to new paradigm of holistic engineering is not a natural transition; it is not an evolutionary process but a revolutionary one! It will take a concerted effort to recast the basic standards of engineering, expanding our expectations of students and demanding a more integrated approach to design and development. It will require engineers who understand and practice the art of systems engineering while thinking holistically and understanding the impacts and ramifications of their creations and innovations [7] [10].

Problem Based Learning (PBL) may be a good alternative to approach change of traditional thinking to holistically thinking of engineers. To understand PBL is necessary talk about its story. PBL dates back to early 1970s. It was developed as a new learning paradigm. PBL was first adopted by the Master Medical School of Canada. With the introduction of PBL in the institution, the curriculum shifted from a faculty-centered to a student-centered, interdisciplinary teaching model. The PBL approach is thought to be well suited especially to medical schools since the skill of life-long learning is critical in this field [12].

Lately, the PBL system has become as popular in several European countries as it is in the United States, because the integration of different disciplines into the curriculum is very important.

Today the PBL system is widely recognised as a strategy for effective learning. In PBL, the learning is triggered by striving to tackle a "problem" which may be presented in many forms such as a description of a design scenario, a curious outcome or an extreme event. Basically, students form teams, organise the work, research and negotiate a response to the problem [19].

Finally, to try of explain briefly the PBL system. In this, the role of the lecturer is to act as a facilitator of learning by defining the problem and then guiding the students along the learning curve. The main aim of PBL is to overcome some of the problems common to the traditional method of "lecture-tutorial" based learning. In the traditional learning method, the knowledge of the lecturer is presented to the students and the learning of the students is tested usually in the form of a final examination with or without laboratory/practical assessment [30].

To improve the teaching-learning process in Mexico, it is necessary that professors interconnect the knowledge obtained by the program curricula horizontally and vertically [24], in order to improve the cognitive process of students in the first semesters, in order to form most critical students [31]. It is due to frequently students ask themselves about the usefulness of some courses, as they do not manage to see any concrete application coming from them [24]. 
PBL was used in some Mexican Private Universities such as, Universidad del Valle de Mexico, Universidad Iberoamericana, and Tecnológico de Monterrey in Bachelors of Social Sciences, improving the teaching-learning process with good results such as, decreased of students failed. So needs the inclusion of PBL in engineering classes [17].

The authors think that, this strategy help can to undergraduate student of environmental engineering's of Universidad del Mar to obtain a holistic view to resolve them proposed problem.

A teaching program project intended for Environmental Engineering undergraduate students at the Universidad del Mar, which includes courses of multivariable calculus, computer programming, numerical analysis, and chemical reactors engineering is proposed herein.

It should be mentioned that the PBL strategy designed here follows the Bologna Declaration in 1999, which points out to the need of reorganization of the European higher education curricula according to a three cycle's structure, suggests a reduction of formal lecture hours and stresses out the importance of autonomous work [22].

As background of the PBL strategy in Del Mar University there are the works titled Problem Based Learning: Obtaining Enzyme Kinetics Parameters Integrating Linear Algebra, Computer Programming and Biochemistry Curriculum. In this work is focused on a project that integrates the curriculum of biochemistry, lineal algebra and computer programming. The purpose is for students to develop a software tool which calculates enzyme kinetic parameters based on proposed data. This program calculates such parameters using a linear regression of one of the linear forms of the Michaelis-Menten equations; moreover it characterizes the confidence of the lineal fit with the correlation coefficient. Once the different proposed steps were accomplished, we concluded that the purpose was satisfactorily reached with an increment in creative ability. The most important fact is that the percentage of failure among students was 57\%, 50\%, 28\% and $18 \%$ from 2005 to 2008 , respectively [23].

In the other hand a PBL strategy was implemented in chemical engineering curriculum in the syllabus of Material balances. The PBL designed is based in: 1. Roles for teamwork, 2. Knowledge previous, 3. Self-Assessment and Peer-Assessment base on a questionarie. The main results set improve student's skills, and diminished the failed students [21] [27].

The design of a PBL strategy is kept similar to the one adopted by Offman and Cadet in 2002 [18], which consists of 3 working sessions of 2 hours each, the first one with an introductory purpose. In these sessions, discussion is encouraged with a minimum involvement of the facilitator [25]. Each session takes place during three days. A written report that answers specific questions is expected in each session.

\section{Problem Description}

The PBL problem dealt with here is the analysis of a continuous stirred tank chemical reactor. The system is based on a first order chemical reaction: $A \stackrel{k 1}{\longrightarrow} B$. The Eq. (1) describes the dynamic model and included parameters are presented in Table 1.

$$
\begin{aligned}
& r(C, T)=k_{o} C e^{-E_{A} / R T} \\
& \frac{d C}{d t}=\theta\left(C_{i n}-C\right)-r(C, T)
\end{aligned}
$$




$$
\frac{d T}{d t}=\theta\left(T_{i n}-T\right)+\Delta H_{r x n} r(C, T)+\gamma(u-T)
$$

Table 1. Kinetic parameters.

\begin{tabular}{|l|l|l|}
\hline Parameter & Value & Unites \\
\hline$\theta$ & 1 & $\mathrm{~min}^{-1}$ \\
\hline$\gamma$ & 1 & $\mathrm{~min}^{-1}$ \\
\hline$\Delta H_{r x n}$ & 200 & $\mathrm{~m}^{3} \mathrm{Kmol}^{-1}$ \\
\hline $\mathrm{u}$ & 350 & $\mathrm{~K}$ \\
\hline$k_{o}$ & $e^{25}$ & $e^{25}$ \\
\hline $\mathrm{E}_{\mathrm{A}} / \mathrm{R}$ & 10000 & $\mathrm{~K}$ \\
\hline $\mathrm{C}_{\text {in }}$ & 1 & $\mathrm{~mol} \mathrm{~m}$ \\
\hline $\mathrm{T}_{\text {in }}$ & 350 & $\mathrm{~K}$ \\
\hline
\end{tabular}

To PBL strategy design the authors using the method of questions and expected answers. This method has the concepts that needs to analysis of chemical reactors.

\subsection{Part I (Session 1)}

The facilitator, in this section, should motivate the students to investigate subjects related with analysis of stirred tank chemicals reactors (CSTR). In order to assist, he can propose the following questions: What is a chemical reactor? What is the CSTR dynamic general model? What is the analysis of chemical reactors? What is the purpose of the analysis of chemical reactors?

\subsection{Part II (Session 2)}

After understanding the analysis of chemical reactors concept, the facilitator must introduce the mathematical tool and outline the following questions: How to solve the dynamic system of chemical reactors? What is multiplicity of stationary states? What is bifurcation analysis? What is a phase portrait? What is hysteresis?

\subsection{Part III (Session 3)}

In this session the students are introduced to the multiplicity of stationary states, bifurcation analysis, hysteresis, and phase portrait, trough the integration of your knowledge acquired. In this section the authors present the answers expected about of analysis of continuous stirred tank reactor with a process control approach.

\section{STUDENTS ASSESSMENT}

It is very important to carry out an activity assessment, which consists of three stages: selfassessment, homogeneous-assessment and heterogeneous-assessment. In the self-assessment stage students are asked to reply questions contained in Table 2 in order to identify their skills and weaknesses in problems solutions. While that the homogeneous-assessment theirs colleagues give the grade after solve exercise, thus, theirs colleagues help in they the academic formation. Finally, the facilitator should value behaviour assessment (attitude and knowledge) of each student. At the end of this test, each student self-evaluates assigning a grade between 0 and 10 [6] [31]. 
Table 2. Students Self-Assessment Questionaire (Based on [21] [23]).

\begin{tabular}{|c|c|c|}
\hline Attitude & & \\
\hline $\begin{array}{l}\text { 1. If I do not understand how to solve a problem, I first try to } \\
\text { understand it? }\end{array}$ & Yes & NO \\
\hline $\begin{array}{l}\text { 2. I was honest with my self-learning (I did not copy; I did my work } \\
\text { without help). }\end{array}$ & Yes & NO \\
\hline $\begin{array}{l}\text { 3. I was fully responsible for my self-learning (I searched for } \\
\text { information, I always looked more in-depth, I took the initiative to } \\
\text { do additional research, and I didn't depend on others to do my } \\
\text { work). }\end{array}$ & Yes & NO \\
\hline 4. I did all the indicated activities. & Yes & $\mathrm{NO}$ \\
\hline $\begin{array}{l}\text { 5. I actively participated in my team and contributed with some proper } \\
\text { ideas. }\end{array}$ & Yes & NO \\
\hline $\begin{array}{l}\text { 6. I was respectful to team resolutions (taken decisions, agreements, } \\
\text { etc.) }\end{array}$ & Yes & NO \\
\hline \multicolumn{3}{|l|}{ Knowledge } \\
\hline 7. I understand all the concepts. & Yes & NO \\
\hline 8. Now I could solve the problem by myself. & Yes & NO \\
\hline 9. From this example, I understand the importance of teamwork. & Yes & NO \\
\hline
\end{tabular}

\section{EXPECTED ANSWERS}

In this section there is answers expected to all questions asked in each part. In first term is defined the concepts about chemical reactors, process control theory, finally is present the analysis of the continuous stirred tank reactor in the problem given.

\subsection{Part I (Session 1)}

The chemical reactor is a vessel designed to contain chemical reactions. Reactions take place inside the reactor, in conditions which can be monitored and controlled for safety and efficiency [13]. Chemical reactors can be designed as either tanks (see Figure 2) or pipes, depending on the needs, and they can vary in size considerably. Small bench top chemical reactor designs are intended for use in labs, for example, while large tanks can be used to make chemicals on an industrial scale [9] [14]. Continuous chemical reactors operate continuously, as long as the materials needed for the reaction are supplied. These are used to create a steady supply of a needed chemical. Continuous reactors are commonly used in the manufacture of industrial chemicals, when the need for a chemical is high and very consistent [1].

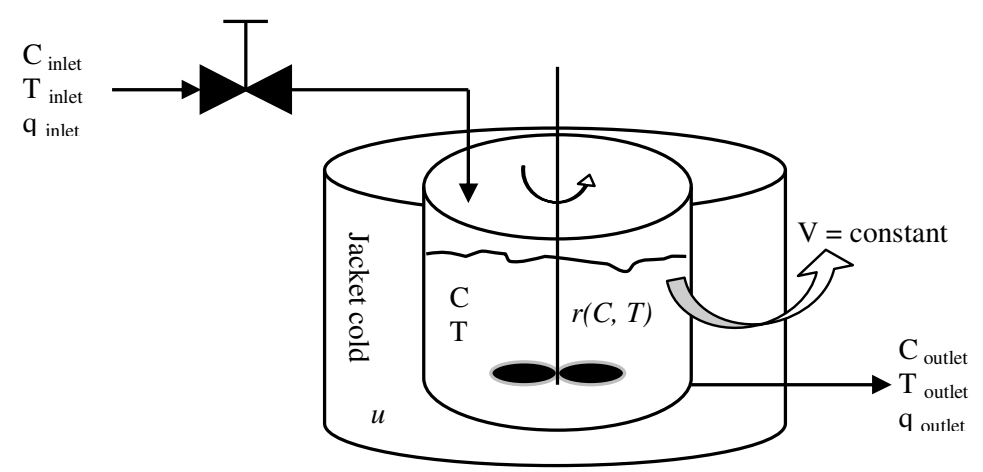

Figure 2. Continuous stirred tank chemical reactors (based on [26] [9] [14]). 
The dynamics of CSTR in which $\mathrm{m}$ reactions take place involving $\mathrm{n}(\mathrm{n}>\mathrm{m})$ chemicals species can be described by equations (1) [25].

$$
\begin{aligned}
& \dot{C}=\theta\left(C_{\text {in }}-C\right)+\operatorname{Er}(C, T) \\
& \dot{T}=\theta\left(T_{\text {in }}-T\right)+\operatorname{Hr}(C, T)+\gamma(u-T)
\end{aligned}
$$

where:

- $C \in \mathbf{R}^{n}$ is the vector of concentrations of chemical species.

- $C_{i n} \in \mathbf{R}^{n}$ is the vector non-negative and constant feed concentrations.

- $T \in \mathbf{R}$ is the vector temperature.

- $T_{i n} \in \mathbf{R}$ is the vector feed temperature.

- $r(C, T) \in \mathbf{R}^{m}$ is the smooth, non-negative, bounded vector of reaction kinetics, with $r(C, T)=0 \forall t \leq 0$.

- $E \in \mathbf{R}^{n} \times \mathbf{R}^{m}$ is the stoichiometric matrix.

- $H(C, T) \in \mathbf{R}^{m}$ is the smooth, bounded row vector of reaction enthalpies, with $H(C, T)=0 \quad \forall t \leq 0$.

- $\theta$ is the reactor dilution rate (i.e. flow rate/volume).

- $\gamma$ is the heat transfer parameter.

- $u$ is the jacket or wall temperature, which is taken as the as the control input.

Non-linearity in models of equations (1) is introduced by the reaction kinetics $r(C, T)$. Commonly, $\mathrm{r}(\mathrm{C}, \mathrm{T})$ has a polynomial or rational dependency on $\mathrm{C}$ and has an Arrhenius dependency on T. Due to this kinetics; CSTRs can display a great variety of dynamic behaviors from multiplicity of steady states to sustained oscillations, including odd attractors.

For detail design of stirred tank chemical reactors is very important the analysis of chemical reactor. From view point of the theory of process control, analysis of chemical reactors includes steady states multiplicity, bifurcation analysis, phase portrait, and hysteresis phenomena. This analysis improves the efficiency of process and safety itself.

\subsection{Part II (Session 2)}

In this section are answer the questions implementing the mathematic tools and physical concepts, such as the methods to solve differential ordinary equation, steady state multiplicity, bifurcation, phase portrait, and hysteresis.

\section{Solve the dynamic system}

The fourth-order Runge-Kutta method is the most accurate than Euler and Taylor methods. This method utilizes several predictor and corrector steps. The predictor values are illustrated in the Figure 3, as well the fourth-order Runge-Kutta method is given mathematically by equations (2). The Runge-Kutta method has an error bounded by $\mathrm{O}\left(\Delta \mathrm{t}^{4}\right)$, which is significantly better than the other methods. 
International Journal of Software Engineering \& Applications (IJSEA), Vol.1, No.4, October 2010

$$
\begin{aligned}
& y_{i+1}=y_{i}+\frac{h}{6}\left(k_{1}+2 k_{2}+2 k_{3}+k_{4}\right) \\
& k_{1}=f\left(x_{i}, y_{i}\right) \\
& k_{2}=f\left(x_{i}+h / 2, y_{i}+h k_{1} / 2\right) \\
& k_{3}=f\left(x_{i}+h / 2, y_{i}+h k_{2} / 2\right) \\
& k_{4}=f\left(x_{i}+h, y_{i}+h k_{3}\right)
\end{aligned}
$$

The equations (2) was deducted using the first five terms of Taylor series, which significant a higher accurate; but the payment is the evaluation of the function $f(x, y)$ four times in each subinterval.

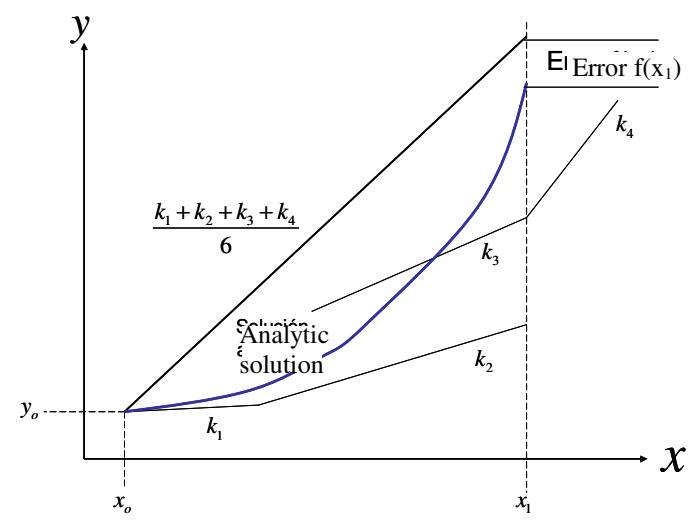

Figure 3. Graphic interpretation of fourth-order Runge-Kutta method.

\section{Multiplicity of Stationary States}

The CSTR could present steady state multiplicity depending of cooling temperature, residence time, and feed temperature such as concentration, in the Figure 3 is shown. To find the steady states is necessary solve the equation (1) assuming that $\mathrm{dC} / \mathrm{dt}=0$ and $\mathrm{dT} / \mathrm{dt}=0$. The equation (1) is reduced to equation (3):

$$
\begin{aligned}
& 0=\theta\left(C_{i n}-C\right)+\operatorname{Er}(C, T) \\
& 0=\theta\left(T_{i n}-T\right)+H r(C, T)+\gamma(u-T)
\end{aligned}
$$

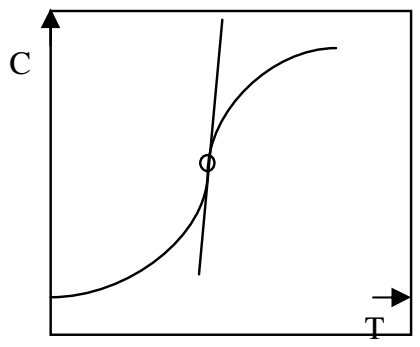

a)

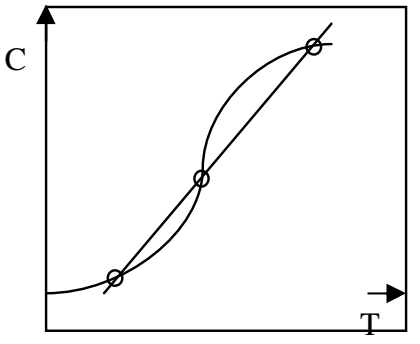

b)

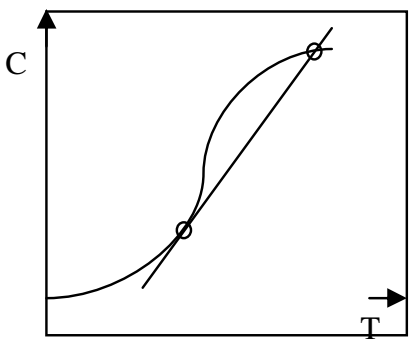

c)

Figure 4. Possible intersections of heat generation curve with line of heat elimination [1]. 
The equation (3) is a nonlinear system, it can solve from Newton method for nonlinear equations system or graphic method. The graphic method is easier than Newton method, but could be inaccurate. The idea to useful the graphic method is that plot the equation (3) and find the possible intersections of heat generation curve with line of heat elimination such as showing in the Figure 4. When the slope of the line of heat elimination is higher than heat generation curve, only there is one intersection, as shown in the Figure 4a, but when the line of heat elimination is more acute there are three or two intersections, such as shown in the Figures $4 \mathrm{~b}$ and $4 \mathrm{c}$ respectively [1].

\section{Bifurcation Analysis}

A bifurcation is a change in the number of candidate operating conditions of a nonlinear system that occurs as a parameter is quasistatically varied. The parameter being varied is referred to as the bifurcation parameter. A value of the bifurcation parameter at which a bifurcation occurs is called a critical value of the bifurcation parameter: Bifurcations from a nominal operating condition can only occur at parameter values for which the condition (say, an equilibrium point or limit cycle) either loses stability or ceases to exist [15].

To fix ideas, consider a general one-parameter family of ordinary differential equation systems as is shown in the equation (4):

$$
\dot{x}=F^{\mu}(x)
$$

Where $x \in \mathrm{R}^{n}$ is the system state, $\mu \in \mathrm{R}$ denotes the bifurcation parameter, and $\mathrm{F}$ is smooth in $\mathrm{x}$ and $\mu$. For any value of $\mu$, the equilibrium points of equation (4) are given by the solutions for $\mathrm{x}$ of the algebraic equations $F^{\mu}(x)=0$.

Local bifurcations are those that occur in the vicinity of an equilibrium point. For example, a small-amplitude limit cycle can emerge (bifurcate) from equilibrium as the bifurcation parameter is varied. The bifurcation is said to occur regardless of the stability or instability of the "bifurcated" limit cycle. In another local bifurcation, a pair of equilibrium points can emerge from a nominal equilibrium point. In either case, the bifurcated solutions are close to the original equilibrium point-hence the name local bifurcation. Global bifurcations are bifurcations that are not local, i.e., those that involve a domain in phase space [15].

If the nominal operating condition of equation (4) is an equilibrium point, then bifurcations from this condition can occur only when the linearized system loses stability. Suppose, for example, that the origin is the nominal operating condition for some range of parameter values.

That is, let $F^{\mu}(x)=0$ for all values of $\mu$ for which the nominal equilibrium exists. Denote the Jacobian matrix of equation (4) evaluated at the origin by equation (5) [5] [15]:

$$
A(\mu):=\frac{\partial F^{\mu}}{\partial x}(0)
$$

\section{Subcritical vs. supercritical bifurcations}

In a very real sense, the fact that bifurcations occur when stability is lost is helpful from the perspective of control system design. To explain this, suppose that a system operating condition (the "nominal" operating condition) is not stabilizable beyond a critical parameter value. Suppose a bifurcation occurs at the critical parameter value. That is, suppose a new candidate operating condition emerges from the nominal one at the critical parameter value. Then it may be that the new operating condition is stable and occurs beyond the critical parameter value, 
providing an alternative operating condition near the nominal one. This is referred to as a supercritical bifurcation. In contrast, it may happen that the new operating condition is unstable and occurs prior to the critical parameter value. In this situation (called a subcritical bifurcation), the system state must leave the vicinity of the nominal operating condition for parameter values beyond the critical value. However, feedback offers the possibility of rendering such a bifurcation supercritical. This is true even if the nominal operating condition is not stabilizable. If such a feedback control can be found, then the system behaviour beyond the stability boundary can remain close to its behaviour at the nominal operating condition [15].

The foregoing discussion of bifurcations and their implications for system behaviour can be gainfully viewed using graphical sketches called bifurcation diagrams. These are depictions of the equilibrium points and limit cycles of a system plotted against the bifurcation parameter. A bifurcation diagram is a schematic representation in which only a measure of the amplitude (or norm) of an equilibrium point or limit cycle need be plotted. In the bifurcation diagrams given in this chapter, a solid line indicates a stable solution, while a dashed line indicates an unstable solution [15].

Several bifurcation diagrams will now be used to further explain the meanings of supercritical and subcritical bifurcation, and to introduce some common bifurcations. It should be noted that not all bifurcations are supercritical or subcritical [15].

Figure 5a serves two purposes: it depicts a subcritical bifurcation from the origin, and it shows a common consequence of subcritical bifurcation, namely hysteresis. A subcritical bifurcation occurs from the origin at the point labelled $\mathrm{A}$ in the Figure. It leads to the unstable candidate operating condition corresponding to points on the dashed curve connecting points A and B. As (the parameter $\mathrm{p}$ is decreased to its value at point $\mathrm{B}$, the bifurcated solution merges with another (stable) candidate operating condition and disappears.

Figure $5 \mathrm{~b}$ depicts a supercritical bifurcation from the origin. This bifurcation is distinguished by the fact that the solution bifurcating from the origin at point $\mathrm{A}$ is stable, and occurs locally for parameter values $\mathrm{p}$ beyond the critical value (i.e., those for which the nominal equilibrium point is unstable).
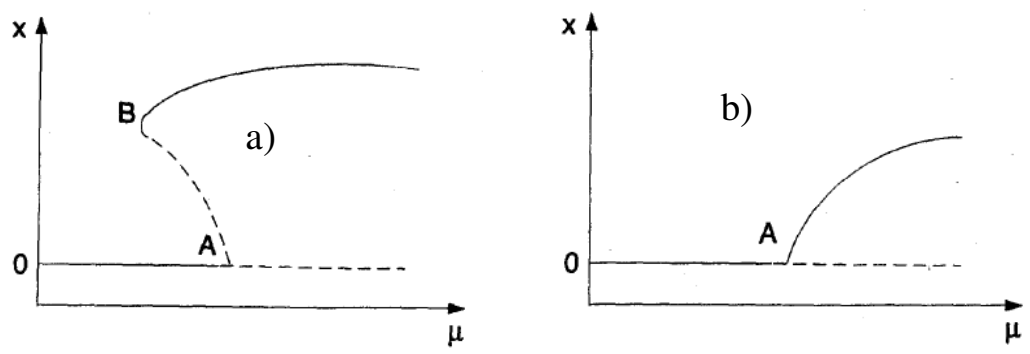

Figure 5. a) Subcritical bifurcation with hysteresis, and b) Supercritical bifurcation [15] [29].

Finally given full information on the nominal equilibrium point, the occurrence of bifurcation is a consequence of the behaviour of the linearized system at the equilibrium point. The manner in which the equilibrium point loses stability as the bifurcation parameter is varied determines the type of bifurcation that arises. 
Phase portrait

There are other graphical techniques for construction of phase portraits. These are discussed in the next paragraph.

\section{Phase Space}

In general, an nth-order dynamic system can be described by II state variables. The state variables $\left(\mathrm{x}_{1}, \mathrm{x}_{2}, \ldots, \mathrm{x}_{\mathrm{n}},\right)$ can be located in a coordinate system called phase space. Each value of $t$, say $t_{1}$, defines a point in this space: $x_{i}\left(t_{1}\right), x_{2}\left(t_{1}\right), \ldots, x\left(t_{1}\right)$. The solution curve is a locus of these points for all values of $t$. It is called a trajectory and connects successive states of the system. As given the general system in the equation (4) [4].

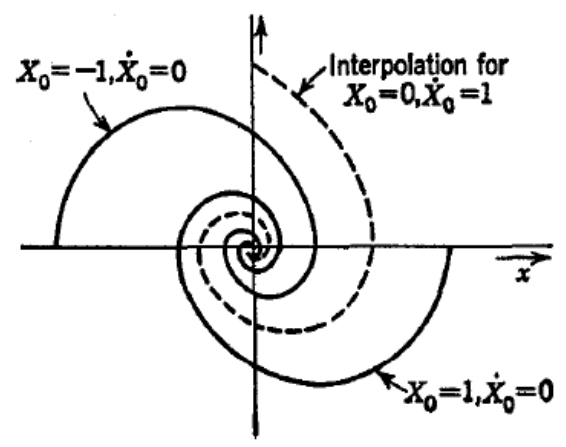

Figure 6. The phase plane [4].

The coordinate system was a plane with an axis for each state variable; we shall refer to this coordinate system as a phase plane. Figure 6 is a typical phase-plane representation of a dynamic system. When the physical system is third-order, the coordinate system consists of three axes, one for each state variable. Of course, systems of fourth- or higher order require treatment in space that is of too many dimensions to be visualized. The graphic aspects of phase-space representation are advantageous primarily in the case of two dimensions (the phase plane) and to a limited extent for three dimensions. The bulk of practical use of phase-space analysis has been made in the two-dimensional autonomous (time invariant) case [4] [20]:

$$
\begin{aligned}
& \frac{d x_{1}}{d t}=f_{1}\left(x_{1}, x_{2}\right) \\
& \frac{d x_{2}}{d t}=f_{2}\left(x_{1}, x_{2}\right)
\end{aligned}
$$

For this reason, we largely confine our attention in the remainder of this study to systems that may be written in the form of equations (6). As we have seen, there is no loss in conceptual generality, but we cannot expect the graphical aspects of the material we shall develop to generalize to higher-dimensional phase space. The solution of the system (6) may be presented as a family of trajectories in the $\mathrm{x}_{2} \mathrm{x}_{1}$ plane. If we are given the initial conditions:

$$
\begin{aligned}
& x_{1}\left(t_{0}\right)=x_{10} \\
& x_{2}\left(t_{0}\right)=x_{20}
\end{aligned}
$$


the initial state of the system is the point $\left(\mathrm{x}_{10}, \mathrm{x}_{20}\right)$ in the $\mathrm{x}_{2} \mathrm{x}_{1}$ plane and the trajectory may, in principle, be traced from this point. By dividing the second of Equations (6) by the first, we obtain de equation (7) [20]

$$
\frac{d x_{2}}{d x_{1}}=\frac{f_{2}\left(x_{1}, x_{2}\right)}{f_{1}\left(x_{1}, x_{2}\right)}
$$

Now $\mathrm{dx}_{2} / \mathrm{dx}_{1}$ is merely the slope of a trajectory, since a trajectory is a plot of $\mathrm{x}_{2}$ versus $\mathrm{x}_{1}$ for the system. Hence, at each point in the phase plane $\left(\mathrm{x}_{1}, \mathrm{x}_{2}\right)$, equation (7) yields a unique value for the slope of a trajectory through the point, namely, $\mathrm{f}_{2}\left(\mathrm{x}_{1}, \mathrm{x}_{2}\right) / \mathrm{f}_{1}\left(\mathrm{x}_{1}, \mathrm{x}_{2}\right)$. This last statement should be amended to exclude any point $\left(\mathrm{x}_{1}, \mathrm{x}_{2}\right)$ at which $\mathrm{f}_{1}\left(\mathrm{x}_{1}, \mathrm{x}_{2}\right)$ and $\mathrm{f}_{2}\left(\mathrm{x}_{1}, \mathrm{x} 2\right)$ are both zero. These important points are called critical points and will be examined in more detail below. Since the slope of the trajectory at a point, say $\left(\mathrm{x}_{1}, \mathrm{x}_{2}\right)$, is by Equation (7) unique, it is clear that trajectories cannot intersect except at a critical point, where the slope is indeterminate [4].

\section{Analysis of Critical Points}

In the situations of most interest to us, equation (6) will represent the behaviour of a (nonlinear) control system. Therefore, we shall be interested in maintaining the system at or near a steady state. Since, from equation (6), a steady-state point is defined by:

$$
f_{1}\left(x_{1}, x_{2}\right)=f_{2}\left(x_{1}, x_{2}\right)=0
$$

it is clear that the steady states are critical points. At the critical points, the slope of the trajectory is undefined; hence, many trajectories may intersect at these points. The oscillatory motion occurs because the system of equations (6) is under damped, as indicated by the characteristic equation given in the equation (9).

$$
|s I-A|=0
$$

For comparison, a typical focus is sketched in Figure 7. In fact, other types of behaviour may be exhibited by critical points of a second-order system, depending on the nature of the roots of the characteristic equation. The distinction between stable and unstable nodes or foci is made to indicate that the trajectories move toward the stable type of critical point and away from the unstable point. The saddle point arises when the roots of the characteristic equation are real and have opposite sign. In this case there are only two trajectories that enter the critical point, and after entering, the trajectories may leave the critical point (permanently) on either of two other trajectories. No other trajectory can enter the critical point, although some approach it very closely [4] [25]. 


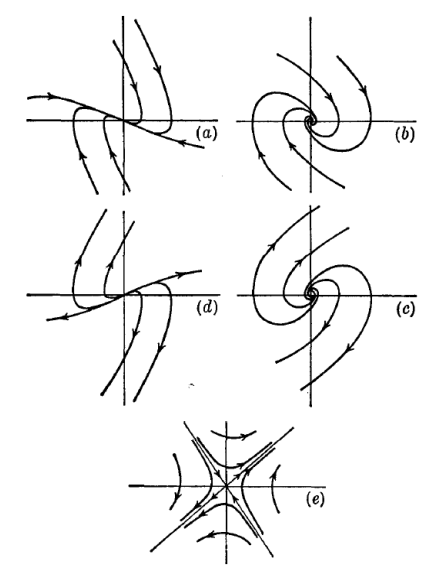

Figure 7. (a) Stable node, (b) Stable focus, (c) Unstable focus, (d) Unstable node, (e) Saddle point [4] [28].

\section{Hysteresis}

In physical sciences hysteresis is referring to situations where equilibrium is path-dependent [2]. This phenomenon produces multiple steady states as we saw in before paragraphs and Figure 8.

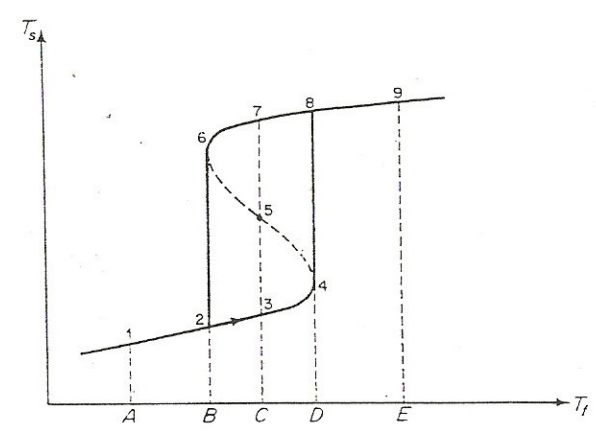

Figure 8. Hysteresis of steady state with feed temperature variation [1].

In the Figure 8 we can observed that if the feed temperature $\left(T_{f}\right)$ increased slowly for arrive speedy the steady state, it continuous to arrive at point 4 with once $\mathrm{D}$ feed temperature. In this point there is an abrupt change, hence if the feed temperature is shifted to the right of the line $\mathrm{D}$ there is only one intersection (right to point 8) and it is far of stationary state (point 4). Therefore, there is a discontinuous jump from point 4 to point 8 , as show in the Figure 8 . It is as the reaction has been inflamed with a feed temperature high. An increase of $T_{f}$ doesn't produce a spectacular change, as shown in the $\mathrm{E}$ line and point 9.

If diminish $\mathrm{T}_{\mathrm{f}}$ slowly, so that heat elimination line pass from $\mathrm{E}$ to $\mathrm{A}$, we can deduce that without extreme perturbation the steady state sequence are the point 9,8,7 and 6 . However, a slight change of the $T_{f}$ down of the $B$ line give only one intersection to left of point 2 and far of the point 6 . It's as the reaction has been "frozen" instantaneously for a feed temperature very cold, show a discontinuity between points 6 and 2 . If we continuous with this procedure, we can observed that we would never find yourself the stationary states between point 4 and 6 , it's due that this steady states are unstable [1]. 


\subsection{Part III (Session 3)}

In Figure 9, is shown the graphic solution of the continuous stirred tank reactor, it was done in Matlab 2010a. Also, we can observe that the setting time is nearly 6 minutes. The stability of the reactor is presented in the next analysis.

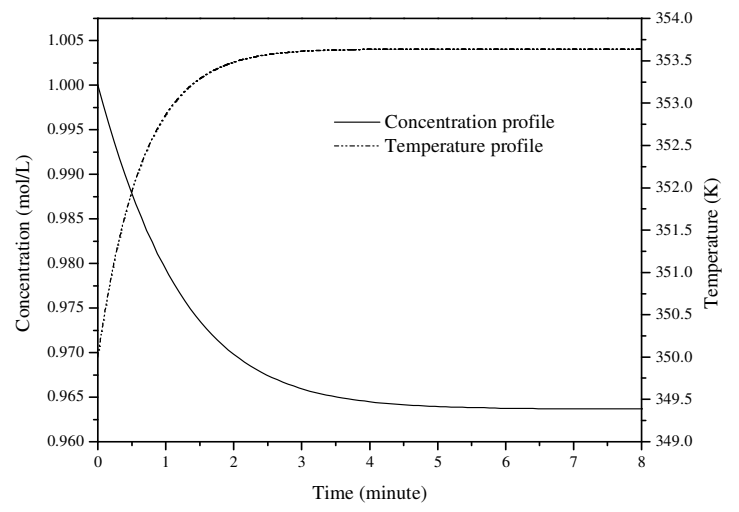

Figure 9. Numerical simulation of the dynamic system.

To obtain the equilibrium points of this case study, it is necessary considering the dynamic system in steady state. Therefore, there are two functions which are shown in equations (10).

$$
\begin{aligned}
& f_{1}(C, T)=\frac{\gamma(T-u)-\theta\left(T_{i n}-T\right)}{\Delta H_{r x n} k_{o} e^{-E_{A} / R T}} \\
& f_{2}(C, T)=-\frac{E_{A}}{R \ln \left[\frac{\theta\left(C_{i n}-C\right)}{k_{o} C}\right]}
\end{aligned}
$$

In Figure 10, is shown the numerical solution of the equations (10). In this Figure's observed that there are three equilibrium points. The $\mathrm{P}_{1}$ and $\mathrm{P}_{3}$ points are stable and $\mathrm{P}_{2}$ point is unstable, this is demonstrated with next procedure:

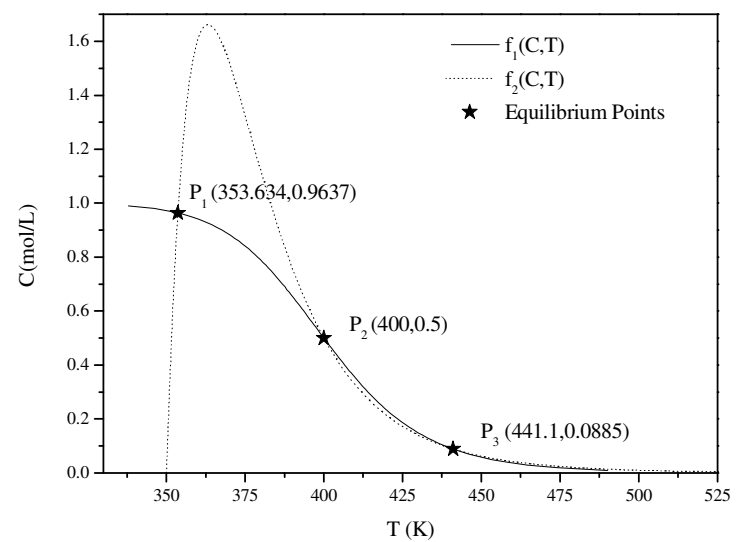

Figure 10. Numerical solution of the equilibrium point. 
International Journal of Software Engineering \& Applications (IJSEA), Vol.1, No.4, October 2010

Step 1. Linearized the dynamic system with Newton series first order, is obtained the equations (11).

$$
\begin{aligned}
& \frac{d C}{d t}=\left.\frac{d C}{d t}\right|_{P}+\left.\frac{d}{d C} \frac{d C}{d t}\right|_{p}\left(C-\left.C\right|_{P}\right)+\left.\frac{d}{d T} \frac{d C}{d t}\right|_{p}\left(T-\left.T\right|_{P}\right) \\
& \frac{d T}{d t}=\left.\frac{d T}{d t}\right|_{P}+\left.\frac{d}{d T} \frac{d T}{d t}\right|_{p}\left(T-\left.T\right|_{P}\right)+\left.\frac{d}{d C} \frac{d T}{d t}\right|_{p}\left(C-\left.C\right|_{P}\right)
\end{aligned}
$$

Step 2. Considering stationary state and rename the next variables $\mathrm{x}_{1}=\left(\mathrm{C}-\left.\mathrm{C}\right|_{\mathrm{P}}\right)$ and $\mathrm{x}_{2}=\left(\mathrm{T}-\left.\mathrm{T}\right|_{\mathrm{P}}\right)$, we can obtain the system equations (12).

$$
\underbrace{\left[\left.\begin{array}{cc}
\left.\frac{d}{d C} \frac{d C}{d t}\right|_{p} & \frac{d}{d T} \frac{d C}{d t}
\end{array}\right|_{p}\right.}_{A} \begin{array}{l}
\left.\left.\frac{d}{d C} \frac{d T}{d t}\right|_{p} \frac{d}{d T} \frac{d T}{d t}\right|_{p} \\
x_{1}
\end{array}]=\left[\begin{array}{l}
0 \\
x_{2}
\end{array}\right]
$$

Step 3. Multiplying the matrix A by identity matrix (I) and determining the $\operatorname{det}(\underset{\sim}{A}-\lambda I)=0$ to obtain eigenvalues solving the second order equation.

$$
\lambda^{2}-\left.\lambda\left(\frac{d}{d C} \frac{d C}{d t}+\frac{d}{d T} \frac{d T}{d t}\right)\right|_{P}+\left.\left(\frac{d}{d C} \frac{d C}{d t} \cdot \frac{d}{d T} \frac{d T}{d t}-\frac{d}{d T} \frac{d C}{d t} \cdot \frac{d}{d C} \frac{d T}{d t}\right)\right|_{P}=0
$$

Step 4. The terms of the matrix A are given in equations (14).

$$
\begin{aligned}
& \frac{d}{d C} \frac{d C}{d t}=-1-e^{25} e^{\frac{-10000}{T}} ; \quad \frac{d}{d T} \frac{d T}{d t}=-2-2000000 e^{25} e^{\frac{-10000}{T}} \frac{C}{T^{2}} \\
& \frac{d}{d T} \frac{d C}{d t}=10000 e^{25} e^{\frac{-10000}{T}} \frac{C}{T^{2}} ; \quad \frac{d}{d C} \frac{d T}{d t}=200 e^{25} e^{\frac{-10000}{T}}
\end{aligned}
$$

Substituting equation (14) in equation (13), we can obtain the characteristic polynomial for find the eigenvalues in each one equilibrium point. Using as stability criteria when two roots are negatives the equilibrium point is unstable. In table 3 , is present the abstract of stability analysis of each equilibrium points.

Table 2. Abstract of stability analysis equilibrium points.

\begin{tabular}{|c|l|c|c|}
\hline Equilibrium point & Characteristic polynomial & Eigenvalues & Stability \\
\hline $\mathrm{P}_{1}$ & $\lambda^{2}+2.45 \lambda+1.45=0$ & $\lambda_{1}=-2.23 \lambda_{2}=-2.66$ & stable \\
\hline $\mathrm{P}_{2}$ & $\lambda^{2}-2.25 \lambda-71.00=0$ & $\lambda_{1}=10.25 \lambda_{2}=-6.25$ & unstable \\
\hline $\mathrm{P}_{3}$ & $\lambda^{2}+2.98 \lambda-3.78=0$ & $\lambda_{1}=-5.43 \lambda_{2}=-0.53$ & stable \\
\hline
\end{tabular}

With phase map is clearly see the stability of each one equilibrium point. These will be shown later. The stability is very important because the unstable equilibrium point lead to the optimal production process. 
In Figure 11, is shown the hysteresis of stationary state with variation in feed temperature. This was obtained with gradual variation of the jacket cold temperature (u). The first step is change (u) in the interval from $300 \mathrm{~K}$ to $400 \mathrm{~K}$ with an increment of $5 \mathrm{~K}$, using the initial conditions of $\mathrm{C}_{0}=[0.001 \mathrm{~mol} / \mathrm{L}, 400 \mathrm{~K}]$. Subsequent, change $(\mathrm{u})$ in the interval from $400 \mathrm{~K}$ to $300 \mathrm{~K}$ with an increment of $5 \mathrm{~K}$, using the initial condition of $\mathrm{C}_{0}=[0.027 \mathrm{~mol} / \mathrm{L} 467.35 \mathrm{~K}]$. The simulation too was done in Matlab 2010a.

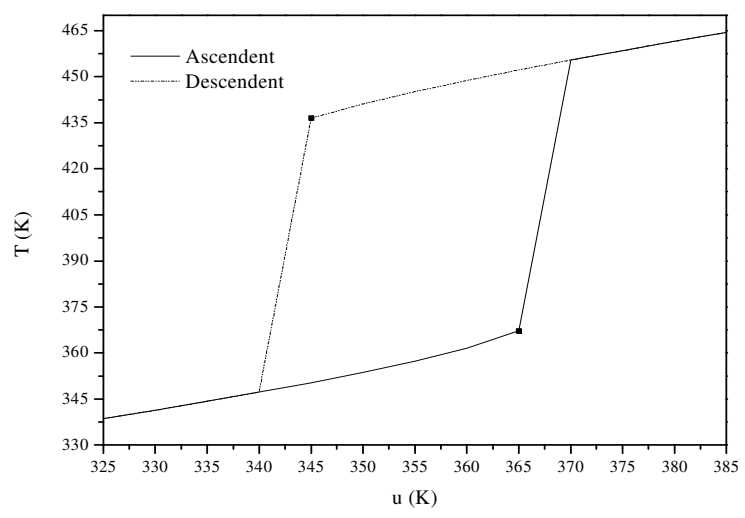

Figure 11. Hysteresis of stationary state with variation in feed temperature.

In addition in Figure 11 we can observed that there is a jump between stable equilibrium points as mentioned Aris (1973).

The bifurcation analysis is given in Figure 12. It is obtained considering the dynamic system in stationary state and rearranging equations (1) such as one expression for energy balance in function of composition and temperature $(\mathrm{u}(\mathrm{C}, \mathrm{T}))$ and the weigh balance in function of temperature $(\mathrm{C}(\mathrm{T}))$. These expressions are shown in the next equations:

$$
\begin{aligned}
& u(C, T)=\frac{\theta\left(T-T_{i n}\right)}{\gamma}-\Delta H_{r x n} k_{o} C e^{-E_{A} / R T}+T \\
& C(T)=\frac{\theta C_{i n}}{\theta+k_{o} e^{\left(-E_{A} / R T\right)}}
\end{aligned}
$$

Finally, an expression for plot the bifurcation analysis is rearranging equations (15), generating the jacket cold temperature in function of reactor temperature, as shown in equation (16).

$$
u=\frac{\theta\left(T-T_{i n}\right)}{\gamma}-\Delta H_{r x n} k_{o} \frac{\theta C_{i n}}{\theta+k_{o} e^{\left(-E_{A} / R T\right)}} e^{-E_{A} / R T}+T
$$
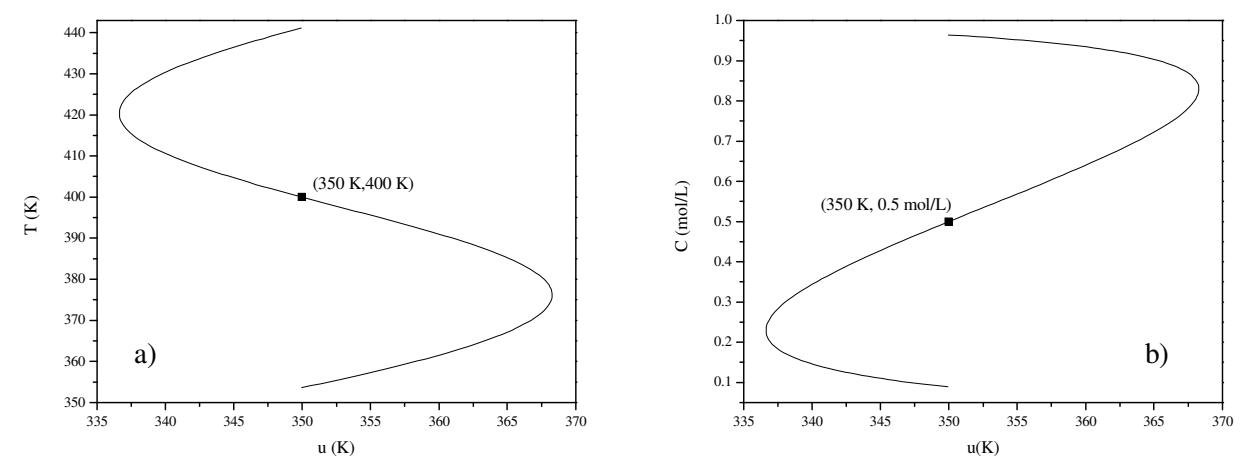

Figure 12. Bifurcation analysis. a) Jacket cold temperature versus reactor temperature, and b) Jacket cold temperature versus concentration. 
In Figure 13, we can see the bifurcation analysis, hysteresis phenomena, and equilibrium point coupled. Also, shows that the equilibrium points overlap in the bifurcation analysis as well hysteresis phenomena.

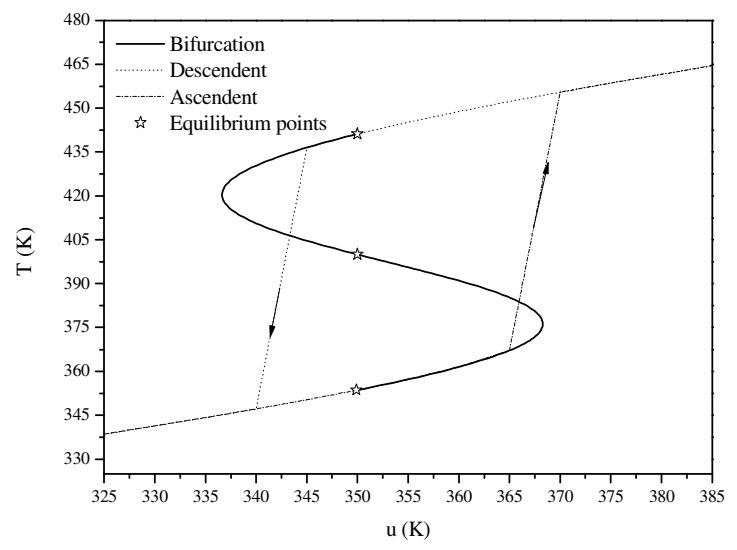

Figure 13. Bifurcation and hysteresis coupled.

In Figure 14 a) and b), are shown the phase map of the equilibrium points $\mathrm{P}_{1}$ y $\mathrm{P}_{3}$ respectively. These were obtained changing the initial conditions. Also shows that to different initial conditions the dynamic system reaches the stationary state at equilibrium points $\mathrm{P}_{1}$ and $\mathrm{P}_{3}$. These is due to this points are stables. As well, only will the reach at equilibrium point $\mathrm{P}_{2}$ implementing a control law, because it's an unstable point.
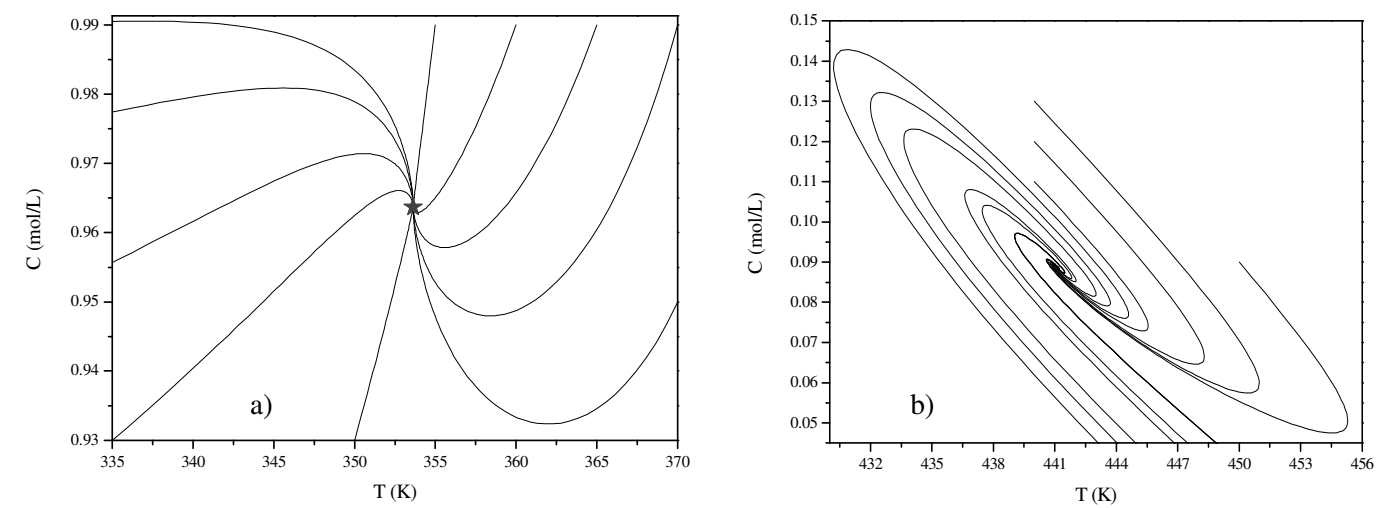

Figure 14. Phase portrait. a) Equilibrium point $\mathrm{P}_{1}$, and b) Equilibrium point $\mathrm{P}_{3}$.

\section{RESULTS}

The proposed PBL strategy was implemented with students of seventh and tenth semester of undergraduate in environment engineering. As professor this practice was interesting, because I could teach to my students in an environment student-centered. To continue shown the assessment of the PBL strategy implemented undergraduate in environment engineering. 


\subsection{Student Assessment}

In Figure 1 we have an analysis of the answers to each question in the student's self-assessment. Most students had a good attitude and understand the concepts.

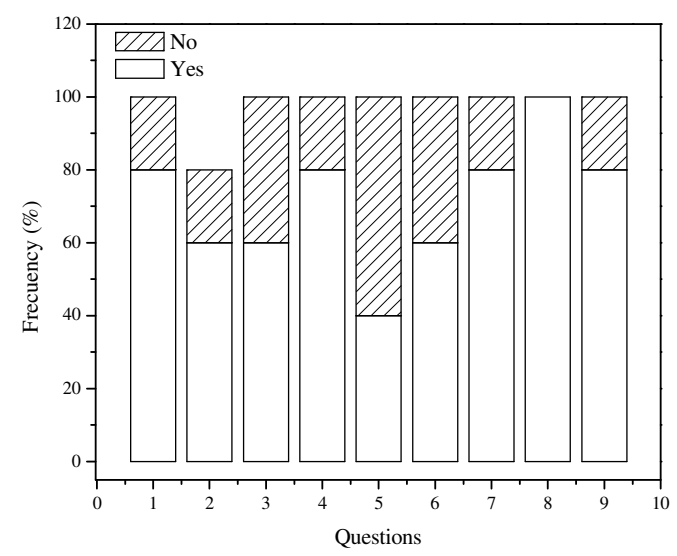

Figure 1. Answers Statistics of the Self-Assessment.

In Figure 2 shown, the points of the three assessment type of each student show that only one student self-reported that he failed, because he likes the traditional learning method more and most were comfortable with PBL, as demonstrated by above average points.

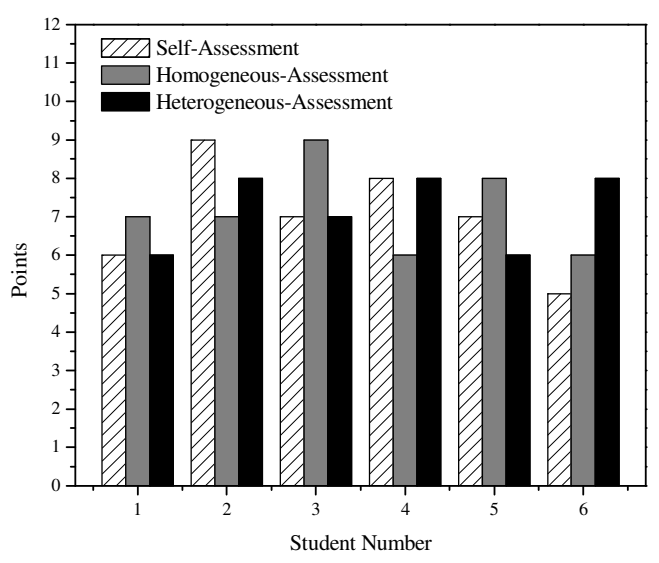

Figure 2. Comparison of the three Assessment Types.

I wish to mention that it's very important to listen to the students, because they can help to improve the learning process between professor and students [24].

\subsection{Student Feedback}

As the proposed PBL strategy was a success, the students stated that, PBL is preferred, because:

a. They can acquire skills at their own pace within a problem solving environment.

b. Learning takes place in a cooperative student-centered, environment.

c. It opens their eyes to how university life should be.

d. PBL improved their generic skills.

e. It makes us feel more comfortable to work in a group to solve problems. 
f. They said that "It really makes us work for ours studies and we feel intelligent doing it".

g. We feel like engineers when we are doing the group assignments.

h. The given problem excites the students' curiosity to know more.

i. It can be described as a double edged sword, because we are required to do more than with traditional learning methods education.

\section{Conclusions}

Once the students concluded each step of the work program, the facilitator of this activity notes a cognitive improvement in the global understanding of the involved discipline, and the objective is satisfactorily attained.

The PBL method is a strong tool to develop the creativity of students, as the prime objective of universities is to produce critical students.

If the objective was attained for the students which had the PBL to solve, it is worth noting that the degree of understanding depends on both the solidity of the knowledge background and the abilities acquired during the academic curriculum, and of the availability of specialists and the leadership of the facilitator involved.

The use of PBL methodology can make the difference in the preparation and formation of students, and this is why it remains important that professors assume their educational role. This supports an updated commitment to the search for learning alternatives, as well as a responsibility of institutions to invest in teaching courses for the improvement of the educational processes.

Finally, the authors of this paper recommend that a curriculum that prepares environment engineering graduates for the challenges they will face in industry should include the following features [16]:

$\checkmark$ A structured approach relying on fundamentals. In this approach, students use process simulators starting in the sophomore material and energy balance course, applying their knowledge to practical problems. Students will then be better prepared for the challenges of the capstone design project and can spend more time on synthesis, controllability, safety, environmental concerns, waste minimization, optimization, and economic evaluation.

$\checkmark$ A balance between heuristic and computer-aided algorithmic approaches. Since design invariably involves significant designer intervention, it is important to teach both heuristics as well as algorithmic methods.

$\checkmark \quad$ Integrated design and control. Instruction should reflect the current state-of-the-art in the integration of process design and process control. The concern here is the need to bridge the gap between traditional process control courses, which emphasize theory, and applications to actual processes.

\section{ACKNOWLEDGEMENTS}

The authors wish to thank to colleague Gerardo Villa for his revisions.

\section{REFERENCES}

[1] Aris R., (1976) Análisis de Reactores, Temas Selectos de Química, Alhambra.

[2] Blanchard O., J., (1987) "hysteresis in Unemployment", European Economic Review, Vol. 31, No. 1, pp. 288-295.

[3] Bloom B. S., (1956) Taxonomy of educational objectives. Handbook I: Cognitive domain. David McKay Co. 
International Journal of Software Engineering \& Applications (IJSEA), Vol.1, No.4, October 2010

[4] Coughanowr D., R., (1991) Process Systems Analysis and Control, Chemical engineering Series, McGraw Hill.

[5] Dangelmayr G., and Oprea I., (2004) Dynamics and Bifurcation of Patterns in Dissipative Systems, Series B, Vol. 12, World Scientific.

[6] Duch B.J., Groh S.E. and Allen D.F., (2001) "The Power of Problem-Based Learning”, Sterling, Virginia.

[7] Felder R., M., and Spurlin J., (2005) "Applications, reliability and Validity of the Index of the Learning Styles”, Int. J. Engng, Vol. 21, No. 1, pp. 102-112.

[8] Felder R., M., and Brent R., (2004) “The ABC's of Engineering Education: Abet, Bloom's Taxonomy, Cooperative Learning, And So on", Proceedings of the 2004 American Society for Engineering Education Annual Conference \& Exposition, American Society for Engineering Education, pp. 1375-1386.

[9] Fogler H., S., (2001) Elementos de Ingeniería de las Reacciones Químicas, Prentice-Hall.

[10] Grasso D., and Brown M.B., (2010) Holistic Engineering Education, Beyond Technology, Springer Science.

[11] Harris A.T., and Briscoe-Andrews S., (2008) "Development of a problem-based learning elective in "green engineering"”, Education for Chemical Engineers, Vol. 3, Nol. 1, pp. 15-21.

[12] Kuru S., (2007) "Problem Based Learning", TREE - Teaching and Research in Engineering in Europe: Problem based and project oriented learning, Isik University, pp. 1-44.

[13] Levenspiel O., (1993) The Chemical Reactor Omnibook, Oregon St Univ Bookstores.

[14] Levenspiel O., (1998) Ingeniería de las Reacciones Químicas, Reverté, S. A.

[15] Levine W., S., (2000) "Design Methods", The Control Handbook, Vol. 1, pp. 952-956.

[16] Lewin D.R., Seider W.D., and Seader J.D., (2002) "Integrated Process Design Instruction", Computers and Chemical Engineering, Vol. 26, No. 2, pp. 295-306.

[17] Mohd S., B., Othman, H., Esa, A., Sulaiman A., and Othman H., (2007) "Adopting Problembased Learning in the Teaching of Engineering Undergraduates: A Malaysian Experience", International Conference on Engineering Education - ICEE 2007, pp. 1-5

[18] Offman B., and Cadet F., (2002) "Problem-based Learning: Redox-active Disulfides in Plant Light Switch", Biochemistry and Molecular Biology Education, Vol. 30, No. 4, pp. 249-254.

[19] O'Grady, G. and Fung J., C., L., (2006) "Do we get effective learners by using PBL?", International symposium on PBL, Republic Polytechnic, Singapore, pp.74-79.

[20] Perlmutter D. D., (1972), Stability of Chemical Reactors, Prentice-Hall.

[21] Ramírez D., and Romero M. A., (2000) "Experiencias implementando la técnica de PBL en una clase de Ingeniería", XVIII Reunión de Intercambio de Experiencias en Educación, ITESM, Campus Monterrey.

[22] Rasteiro M.G., et al., (2009) "LABVIRTUAL-A virtual platform to teach chemical”, Education for Chemical Engineers, Vol. 4, No. 1, pp. e9-e19.

[23] Regalado-Méndez A., Báez-González, J., G., and Peralta-Reyes, E., (2010), "Problem Based Learning: Obtaining Enzyme Kinetics Parameters Integrating Linear Algebra, Computer Programming and Biochemistry Curriculum", Journal of Communication and Computer, Vol. 11 , No. 7, in press.

[24] Regalado-Méndez A., Báez-González, J., G., Peralta-Reyes, E., and Trujillo-Tapia, M., N., (2010) "Problem Based Learning: Obtaining Enzyme Kinetics Parameters Integrating Linear Algebra, Computer Programming and Biochemistry Curriculum”, Technological Developments in Networking, Education and Automation, Springer, Chapter 3, pp. 13-18.

[25] Regalado M., A., and Álvarez-Ramírez J., (2007) “Composition Linear Control in Stirred Tank Chemical Reactors", New Mathematics and Natural Computation, Vol. 3, No. 3, pp. 385-398. 
International Journal of Software Engineering \& Applications (IJSEA), Vol.1, No.4, October 2010

[26] Regalado M., A., (2003) "Control Lineal de Composición en Reactores Continuos con Estructuras básicas de Control”, Master in Science Thesis, UAM-Iztapalapa.

[27] Rossiter D. and Biggs C. A., (2008) "The trials and tribulations of implementing a problem based learning approach in the freshman year of undergraduate chemical Engineering", AIChECEE Proceadings.

[28] Seydel R., (1998) From Equilibrium to Chaos, Practical Bifurcation and Stability Analysis, Elsever.

[29] Vardoulakis I., (2005) Bifurcation Analysis in Geomechanics, Blackie Academic \& Professional.

[30] Venkatesan S., Molyneaux T., C., and K., Setunge S., (2007). "An Evaluation of Problem Based Learning in Civil Engineering", International Conference on Engineering Education \& Research, Melbourne, Australia, pp. 1-6.

[31] White, H., B., (2003) "Problem-based Learning: Commentary Problem-based Learning and Becoming a Physician”, Biochemistry and Molecular Biology Education, Vol. 31, No. 5, pp. 337-343.

[32] Yang T., and Wang N., (2008) "The Cultivation of Cluster's Sustainable Competence Based on Knowledge Management”, International Journal of Business and Management, Vol. 3, No. 7, pp. 83-88.

[33] Zulkifli M.N., (2009) "Improving Generic Skills among Engineering Students Through Problem Based Learning in Statistics Engineering Course", European Journal of Scientific Research, Vol. 3, No., 2, pp. 270-278.

\section{Authors}

Alejandro Regalado-Méndez received his M.Sc., and B.Sc. in Chemical Engineering from Universidad Autónoma Metropolitana, México in 2003 and 2001, respectively. He researches Simulation and Process Control. He has been professor of Environmental Engineering since September of 2003 at Universidad del Mar, México.

Ma. del Rosario P. Cid-Rodríguez received her M.Sc. in Environmental Education from Universidad Autónoma de Guadalajara, México in 2006, and her B.Sc. in Biology from Universidad Autónoma Metropolitana, México in 1990. He has been professor since 1993 at Universidad del Mar, México. She researches General System Theory and Environment Education.

Juan G. Báez-González received his $\mathrm{PhD}$, M.Sc., and B.Sc. in Chemical Engineering from Universidad Autónoma Metropolitana, México in 2008, 2002 and 1999, respectively. He researches Characterization of Food Dispersed Systems, and Chemistry and Technology of Food. He has been professor of Food Science since February of 2008 at Universidad Autónoma de Nuevo León. Finally, he is member of Mexican Research System in level 1
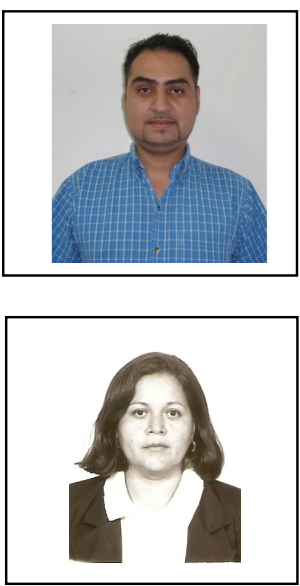
since January of 2008. 